\title{
Dieu et les gènes: une histoire
}

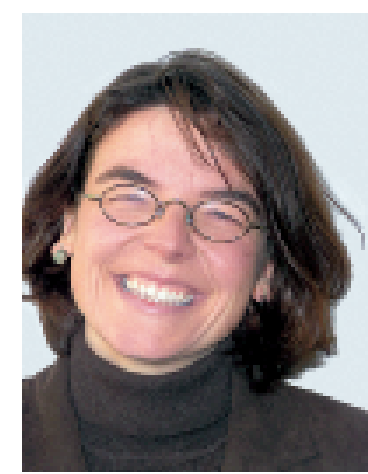

Christina Aus der Au Heymann

* Mme Christina Aus der Au, docteur en théologie, travaille au département de théologie et de dogmatique de l'Université de Bâle et est membre de la rédaction d'éthique du Bulletin des médecins suisses.

Gott und Gen. Auf der Suche nach den biologischen Grundlagen der Religiosität

Journée de conférence publique avec Dean Hamer,

de l'Université de Bâle

Samedi 10 février 2007, 9h15-17h30, Kollegiengebäude de I'Université, Petersplatz, Aula

Entrée libre

Programme et autres informations par internet: www.unibas.ch/ theologie $\rightarrow$ News
Un professeur de théologie systématique reçoit un courriel. Pas de quoi en faire une histoire, sauf que ce dernier a une particularité, celle de provenir d'un professeur d'hématologie.

Les théologiens et les médecins ont aussi peu à faire entre eux que les cerfs et les chevreuils dans la forêt. Partageant le même univers, ils sont en compétition pour trouver leur difficile subsistance, mais s'ignorent la plupart du temps intentionnellement.

C'est là qu'intervient le courriel. Le médecin a lu un livre sur le sujet duquel il aimerait discourir avec le théologien. L'ouvrage est consacré aux bases biologiques de la religiosité, comme le suggère le sous-titre (How Faith is Hardwired into our Genes) et de manière plus pointue, le titre: «The God Gene» (le gène de Dieu).

L'auteur, américain, est chercheur en cancérologie et généticien. Il aurait trouvé un gène qui donnerait à ses porteurs une tendance religieuse plus significative qu'à d'autres congénères. Ce qui signifie qu'ils vivraient davantage d'expériences dans lesquelles les frontières entre la propre conscience et l'entourage se confondent. Ils se sentiraient faire partie d'une grande unité qui les réunirait à d'autres humains, à la nature et au surnaturel.

Un sujet qui devrait intéresser le théologien. Sommes-nous plus ou moins programmés pour la spiritualité? La religiosité est-elle l'affaire d'une prédisposition génétique, comme les yeux bleus et les cheveux blonds? «Ganz de Bappe» (tout comme son père), selon la chanson du trio Eugster dans les années 70 sur un enfant dans sa poussette, mais aussi dans celle de la pasteure en parlant de ses confirmands. La religiosité peut-elle être un talent naturel, favorisant la lutte évolutionnaire pour la survie, qui apporte optimisme, force de vie et espoir? Ou l'idée est-elle absurde, Dieu, la foi et la spiritualité étant des phénomènes tout autres que ceux que l'on peut observer au microscope et décrire de manière scientifique? La question de la disposition génétique pour la religiosité est-elle aussi erronée, en termes de catégories, que celle demandant «De quelle couleur est Dieu»?

Le théologien se dit intéressé. Il ne trouve pas étrange que le vécu religieux et les sentiments soient représentés dans le cerveau et que les dispositions génétiques puissent y être pour quel- que chose. Mais il ne voudrait pas réduire la foi et Dieu à un tel schéma, ni non plus à des expériences sublimes et mystiques. Le cas normal de la foi est plus prosaïque et consiste à vivre dans la confiance de la présence de Dieu. Même si l'expérience n'apporte aucune émotion.

Et pourtant, qu'est-ce que cela signifie si la foi, ou du moins la disposition à s'ouvrir aux expériences qui sortent de l'ordinaire, reposent sur une base génétique? Qu'est-ce que cela signifie en matière de prétention à la vérité de divers projets de foi ou de vie? Qu'est-ce que cela signifie vraiment, lorsqu'à l'instar des valeurs de comportement, les facultés intellectuelles sont elles aussi génétisées? Si tout comme l'agressivité, la dépendance et l'homosexualité, on peut aussi investiguer sous l'angle de leurs propriétés génétiques l'intelligence, la morale et la spiritualité? Qu'est-ce que le scientifique entend en fait par le terme «conditions génétiques»? Le programme, le code, le logiciel de notre vie? Un aspect d'un système qui se reproduit génétiquement et épigénétiquement comme un tout? Quel rôle jouent notre responsabilité, notre individualité, notre personnalité? Qui peut expliquer la génétique? Qui explique le monde, l'homme?

Le médecin et le théologien ne se limitent plus depuis longtemps à ne parler que de cet ouvrage. Et ils ne discutent plus tous seuls. Ils décident d'organiser une journée de débat et souhaitent inviter l'auteur du livre, ainsi qu'une autre auteure provocatrice qui, elle, étudie en analogie avec l'évolution génétique, l'évolution de l'histoire de l'humanité et de la culture. Au lieu du mot «GEN», elle utilise celui de «MEM», le virus de l'évolution culturelle. Elle compare les idées religieuses et les représentations de Dieu avec ces «MEM», qui sont contagieux et peuvent se répandre parfois comme une épidémie. Ces thèses seront commentées par quelques voix critiques, celles d'un biologiste moléculaire et d'un éthicien, d'une chercheuse scientifique, d'un neuropsychiatre et d'une théologienne. La journée sera publique, avec entrée libre. Et les exposés sont destinés à être compris par le tout venant. On y parlera de choses qui intéressent certainement un plus grand public que celui des médecins et des théologiens.

Christina Aus der Au Heymann* 